\title{
Observações sobre o TESA blot no diagnóstico sorológico da doença de Chagas
}

\author{
Observations on the use of TESA blot for the serological \\ diagnosis of Chagas' disease
}

\author{
Vicente Amato Neto ${ }^{1}$, Cláudia Regina De Marchi ${ }^{1}$, Cláudio Santos Ferreira ${ }^{1}$ \\ e Antonio Walter Ferreira ${ }^{2}$
}

\begin{abstract}
RESUMO
Comparamos o TESA blot com a hemaglutinação indireta, imunofluorescência indireta e ELISA. Nos 30 soros de pessoas infectadas pelo Trypanosoma cruzi, as quatro técnicas foram positivas em todos, e nos 30 não-infectados, totalmente negativas. Nos soros indeterminados e nos de leishmaniose visceral, comprovamos muitas positividades falsas, em quantidade bastante menor com o TESA blot.
\end{abstract}

Palavras-chaves: Doença de Chagas. TESA blot. Diagnóstico sorológico.

\begin{abstract}
TESA blot was compared with indirect hemagglutination, indirect immunofluorescence and ELISA tests. In sera from 30 participants infected with Trypanosoma cruzi, and in 30 non infected the four techniques produced entirely equivalent results, all positive and all negative, respectively. In cases admitted to be inconclusive or in visceral leishmaniasis, frequent false positives were detected. However, TESA blot contributed with the least proportion of them.
\end{abstract}

Key-words: Chagas' disease. TESA blot. Serological diagnosis.

O diagnóstico da doença de Chagas depende comumente do resultado de provas sorológicas, sobretudo na fase crônica da infecção parasitária. A disponibilidade de tais procedimentos não só possibilita o reconhecimento etiológico, como também permite, entre outras utilidades, realizar inquérito epidemiológico, controle de tratamento específico e triagem de doadores de sangue.

Com frequiência tem havido poposição de novos tipos de exames em especial relacionados com mudanças de antígenos e de metodologias, sendo procurados aprimoramentos a propósito de sensibilidade ou especificidade, como ainda de execução mais simples e menos custosa.

Agora foi idealizada mais uma prova, designada TESA blot, calcada no uso de extrato de formas tripomastigotas do Trypanosoma cruzi em reações de immunoblotting.

0 antígeno imunodominante semipurificado denominado TESA (Trypomastigote Excreted-Secreted Antigen), contém em sua composição estrutural o SAPA (Shed Acute Phase Antigen) e outros componentes, ainda não identificados, que migram em reações de immunoblotting na região entre 130-200 kDa (encontrados na fase aguda da doença) e 150-160 kDa (encontrados na fase crônica). Este antígeno extremamente sensível e específico constitui objeto de pesquisas no Laboratório de Protozoologia do Instituto de Medicina Tropical de São Paulo. Por ser um shedado de formas tripomastigotas do T. cruzi, o TESA não tem demonstrado reatividade cruzada.

Comparamos o desempenho do TESA blot produzido por bioMérieux Brasil SA com o de técnicas habitualmente utilizadas: hemaglutinação indireta (HI), imunofluorescência indireta (IFI) e ELISA.

Para as comparações empregamos amostras de soro humano glicerinado $(1: 1, \mathrm{v} / \mathrm{v})$ que estavam mantidas a $4^{\circ} \mathrm{C}$.

Compusemos quatro Grupos, cada um com 30 soros, examinados através da HI, IFI (IgG e IgM) e ELISA: I- as três provas positivas, além de confirmação parasitológica; II- as três provas negativas; III- discordâncias entre as três provas,

\footnotetext{
1. Laboratório de Investigação Médica-Parasitologia do Hospital das Clínicas da Faculdade de Medicina da Universidade de São Paulo, São Paulo, SP. 2. Laboratório de Investigação Médica-Soroepidemiologia do Hospital das Clínicas da Faculdade de Medicina da Universidade de São Paulo, São Paulo, SP, Brasil. Endereço para correspondência: Prof. Vicente Amato Neto. LIM/FM/USP. Av. Dr. Enéas de Carvalho Aguiar 500, 05403-000 São Paulo, SP, Brasil. Fax: $55113066-7042$

e-mail: amatonet@usp.br

Recebido para publicação em 15/3/2005

Aceito em 6/9/2005
} 
tornando o resultado final qualificável como duvidoso ou indeterminado; IV- soros de pacientes com leishmaniose visceral parasitologicamente confirmada e ainda não tratados especificamente.

Todos os 120 soros foram também analisados por meio do TESA blot.

Quanto às técnicas adotadas, elas foram, para HI, IFI e ELISA, respectivamente as indicadas por Hoshino-Shimizu e cols $^{2}$, Camargo ${ }^{1}$ e Voller e cols ${ }^{4}$, convindo contudo registrar, em prosseguimento, alguns detalhes a respeito delas.

Hemaglutinação indireta: diluição inicial a 1/20, em solução salina tamponada; kit: CECON - Centro de Controle de Produtos para Diagnósticos Ltda.

Imunofluorescência indireta: diluição inicial a 1/20, em solução salina tamponada; antígenos: formas epimastigotas do Trypanosoma cruzi de cultura (CECON - Centro de Controle de Produtos para Diagnósticos Ltda); conjugado: imunoglobulinas $\mathrm{G}$ e $\mathrm{M}$ anti-humanas, marcadas com isotiocianato de fluoresceína (bioMérieux Brasil SA).

ELISA: soro diluído a 1/201; kit: Hemobio Chagas HBK 401, ELISA - (Embrabil - Empresa Brasileira de Biotecnologia SA.); leitura da absorbância: 450nm, em ELISA-LP 400 Microplate Reader.

TESA blot: por tratar-se de sistema recomendado recentemente, julgamos conveniente citar as etapas para a efetivação desse processo; teste imunoenzimático por Western-blotting; as 24 fitas sensibilizadas com proteínas do antígeno TESA do T. cruzi, separadas imunoeletroforeticamente de acordo com sua massa molecular e transferidas para membrana de nitrocelulose pronta para uso, são acondicionadas nas devidas canaletas, acrescentando-se soro humano diluído a 1:100; após duas horas de incubação em agitador tipo gangorra, aspira-se o conteúdo das 120 canaletas e procede-se a quatro lavagens de cinco minutos com solução apropriada; conjugado anti-IgG humano peroxidase é adicionado, ocorrendo nova incubação de uma hora no mesmo agitador e, após, mais quatro sequiências de lavagens de cinco minutos; há, então, incubação no agitador citado, durante dez minutos, da solução cromógena (4cloro-alfa-naftol) diluída a 1:5; aspira-se o conteúdo de cada canaleta e realiza-se duas lavagens breves; a seguir, transfere-se as tiras de nitrocelulose, com o auxílio de pinça plástica, para papel de filtro e depois de secagem completa ao ar livre efetua-se a leitura: reações positivas com presença de bandas na região de massa molecular de 120-200 kDa e reações negativas com ausências destas.

Nos soros positivos da casuística os valores foram: HI diluição a 1/40 ou maior; IFI (IgG) diluição a 1/40 ou maior; ELISA - média de valor de leitura em torno de 2.9278, cutoff em 0,325 e zona cinza de 0,292 a 0,357; TESA blot conforme assinalado na descrição do método.

Os resultados estão na Tabela 1 . Ficaram evidentes as concordâncias verificadas no Grupo I e no Grupo II, compostos por soros de pessoas sem dúvida infectadas pelo T. cruzi ou das sorologicamente negativas. Então, viu-se comportamento satisfatório do TESA blot.
Tabela 1 - Positividades de acordo com as quatro provas comparadas e com os quatro Grupos considerados.

\begin{tabular}{lrrrc}
\hline Grupo & HI & IFI & ELISA & TESA blot \\
\hline I & 30 & 30 & 30 & 30 \\
II & 0 & 0 & 0 & 0 \\
III & 16 & 23 & 14 & 6 \\
IV & 22 & 27 & 22 & 2 \\
\hline
\end{tabular}

Na IFI não houve positividade para IgM.

O Grupo III contém as positividades que compuseram os resultados indeterminados. É possível perceber os números de participações variadas de cada tipo de exame. 0 número correspondente ao TESA blot foi nitidamente menor, indicando que ele participou menos nessa condição de indefinição, sem porém ter tido comportamento capaz de evitar o problema. Valorização de só um teste negativo gera inadequação em atividade assistenciais, epidemiológicas e científicas, sendo imperioso lembrar que algo dessa natureza freqüentemente faz parte de laudo compatível com indefinição. Entre os 30 casos, o TESA blot resultou negativo em 24, sem conduzir a eventual solução, já que também esteve envolvido na disparidade, marcada por 6 positividades.

No Grupo IV, dos 30 soros de doentes com leishmaniose visceral devidamente comprovada parasitologicamente, a positividade do TESA blot foi de 2 casos.

Sem dúvida, tal casuística é expressiva e útil para obter mais conhecimentos acerca de tópico que suscita falsas positividades. Como verificações surgiram informes significativos quando em foco o diagnóstico sorológico da doença de Chagas. Deparamos com comuns positividades por meio de HI, IFI e ELISA e, contrastando com isso, o TESA blot quase não se portou dessa maneira. A ocasional presença de doença de Chagas nesses doentes é, para nós, desconhecida; todavia, deve ser muito improvável sensível influência de tal ordem no contexto geral. A falsa positividade atribuível à leishmaniose visceral precisa sempre ser cogitada, a fim de evitar más interpretações. A pequena presença do TESA blot é assunto para investigações posteriores.

\section{REFERÊNCIAS BIBLIOGRÁFICAS}

1. Camargo ME. Introdução às técnicas de imunofluorescência. Revista Brasileira de Patologia Clínica 10: 57-71, 87-107, 143-171, 1974.

2. Hoshino-Shimizu S, Camargo ME, Shimizu T, Nagasse TK. A study on the reproducibility of a stable, lyophilized reagent for the Chagas' disease hemagglutination test: proposals for quality control analysis. Revista do Instituto de Medicina Tropical de São Paulo 24: 63-68, 1982.

3. Umezawa ES, Nascimento MS, Kesper Jr N, Coura JR, Borges-Pereira J, Junqueira AC, Camargo ME. Immunoblot assay using excreted-secreted antigens of Trypanosoma cruzi in serodiagnosis of congenital, acute, and chronic Chagas' disease. Journal of Clinical Microbiology 34: 2143-2147, 1996.

4. Voller A, Draper C, Bidwell DE, Bartlett A. Microplate enzyme-linked immunosorbent assay for Chagas' disease. Lancet 1: 426-428, 1975. 